\title{
Os estudantes de odontologia e a leitura de textos acadêmico-científicos no mundo virtual(a)
}

\author{
Jurema Nogueira Mendes Rangel*
}

* Mestre em Educação

\section{RESUMO}

Buscando compreender as práticas de leitura dos estudantes em relação a leitura de textos acadêmicocientificos disponíveis no mundo virtual, o estudo questionou: como os estudantes realizam a leitura destes textos? Como interagem com antigas e novas tecnologias de leitura? Chartier, Levy e Rouet fundamentaram o estudo. O questionário foi o instrumento aplicado em 46 estudantes do $7^{\circ}$. e $8^{\circ}$. períodos de uma universidade particular. Foram entrevistados 3 alunos para esclarecer aspectos evidenciados no questionário. O estudo verificou que o mundo digital faz parte do cotidiano dos alunos. No entanto, estes ainda não demonstraram o letramento proporcionado pela tecnologia, pois dispensam links, o uso da base de dados e preocupam-se em ler texto curtos, eletrônicos ou impressos, porque mais fáceis de serem compreendidos. Utilizam a mesma estratégia de leitura para esses tipos de texto. Concluiu-se que os alunos não são navegadores/leitores proficientes de textos eletrônicos científicos.

\section{DESCRITORES}

Educação em odontologia. Leitura eletrônica. Leitura acadêmica.

$\Delta$ efetiva presença da internet no cotidiano induz a pensar que este meio de acesso a diferentes tipos de textos seja uma realidade na vida dos estudantes.

Não há como negar que a juventude atual é usuária desta ferramenta que a insere na cultura virtual, consumindo um tempo razoável do seu dia a dia. Chats, fóruns, blogs, twiters e outros são espaços eletrônicos que integram o cotidiano do alunado, porém, há, ainda, poucas informações sobre como são apro- veitados para os estudos acadêmicos. As reflexões feitas neste estudo se fazem fundamentais à medida que se quer entender o que significa, num ambiente acadêmico e para adultos universitários, a leitura de textos científicos disponíveis no meio eletrônico. Tal preocupação sobre o processo de ler na academia sedimenta-se na experiência de magistério lecionando disciplinas voltadas para o trabalho de conclusão de curso e metodologia científica, que oportunizou observar e obter dados sobre a dificuldade de leitura dos alunos na graduação.

Em estudo recente, dos 70 estudantes calouros consultados do curso de odontologia, $70 \%$ preferiam usar a internet para buscar informações sobre temas abordados em aula do que ler os textos impressos indicados pelos docentes, principalmente, quando lhes era exigido pesquisa ou estudo específico. ${ }^{16} \mathrm{No}$ entanto, tal resultado não permite afirmar que sejam leitores competentes, muito menos, levando-se em conta que a leitura na universidade demanda uma complexidade de relações, como a delimitação do assunto, contextualização do problema, princípios de classificação, análise, síntese e inferências, bastante diferente da leitura exigida no ensino médio. As leituras técnicas ou acadêmicas/científicas - leituras de estudo, solicitadas na graduação, em grande número, dizem respeito à profissão escolhida. São escritos filosóficos, didáticos, de divulgação científica (artigos e ensaios) e científicos (teses e dissertações) que exigem procedimentos cognitivos específicos.

Assim, buscando compreender as formas de ler dos estudantes no que diz respeito à leitura de estudo que incluem também o texto eletrônico, este artigo busca refletir sobre como os estudantes vêm lidando com a leitura de textos acadêmico-científicos eletrônicos; como interagem com novas tecnologias de lei-

\footnotetext{
${ }^{(a)}$ Este artigo é um aprofundamento do trabalho intitulado "O universitário e as práticas de leitura de estudo: entre o impresso e o eletrônico”, apresentado no $17^{\circ}$ COLE - Congresso de Leitura do Brasil, em Campinas, 2009.
} 
tura, sabendo-se que a prática de leitura digital - o letramento na cibercultura - conduz às ações leitoras diferentes daquelas realizadas nos textos impressos, e por último, de que forma os docentes podem auxiliar a implementação da leitura de material eletrônico para o aprofundamento do conhecimento do aluno.

\section{A leitura: concepções e considerações sobre os textos acadêmico-científicos na graduação}

Além materiais impressos presentes no cotidiano dos estudantes e de textos com os quais se defrontam no meio eletrônico, ambos de caráter variado, há um conjunto de escritos que possui características específicas e atendem a um público intencionalmente determinado, se se pensar no ambiente universitário, o que significa criar a expectativa de um leitor que realize uma leitura mais cadenciada, lenta, cuidadosa, de um tipo de texto classificado como gênero acadêmico.

Adota-se, aqui, a visão de que leitura como um diálogo que o leitor estabelece com o autor, em função do significado do texto. A experiência do leitor é indispensável para construir o sentido, não há leituras autorizadas num sentido absoluto, mas apenas reconstruções de significados, algumas mais outras menos adequadas, segundo os objetivos e intenções do leitor. ${ }^{10}$

A leitura é vista como ações ou reações psicolingüísticas vivenciadas pelo leitor no ato de ler que contém mecanismos lingüísticos (fonológicos, sintáticos, semânticos, pragmáticos) e psicológicos intervenientes na aquisição da leitura, o que implica em operações cognitivas de ordem superior, como a inferência, a evocação, a analogia, a síntese e a análise que supõe uma faculdade necessária composta pela linguagem, compreensão, memória. ${ }^{10}$

A comunicação verbal é fundamental para que a relação cooperativa entre leitor/autor se estabeleça. Os esquemas ou conjunto de habilidades acionados pelo leitor favorecem a percepção da estrutura do texto, a inferência do tom, a intenção, a atitude do autor (atribuição de sentido), a capacidade de parafrasear. Os processos de compreensão são desencadeados no momento da leitura. As dificuldades que porventura surjam podem ser determinadas tanto pelo texto, com sua estrutura e marcações formais como pelo leitor.

Na visão de Coracini ${ }^{6}$ (1995), há certo número de leituras, (através das chamadas inferências autorizadas) que impossibilita outras, portador de significa- dos limitados pelo texto. $\mathrm{O}$ texto tem primazia sobre o leitor que precisa, com competência, apreender o (s) sentido(s) nele inscrito(s).

Essa "flexibilidade" marca a leitura como uma atividade individual, que demanda competências próprias de um leitor ideal, que considere o texto e suas possíveis leituras. Por isso, a leitura sofre alterações de um leitor para outro, pois os conhecimentos prévios, as estratégias de leitura próprias de cada um e as habilidades lingüísticas necessárias distinguem um leitor mais proficiente ou não. O leitor proficiente é aquele que transita pelas marcas deixadas pelo autor para descobrir as suas idéias. ${ }^{10}$

O processamento informação remete ao entendimento de que a leitura compreensiva depende tanto do texto (forma) quanto do leitor, à medida que ele pode monitorar a sua atividade de ler, percebendo quando necessita predizer, hipotetizar, inferir, confirmar as suas hipóteses, o que se traduz no reconhecimento de palavras, o tamanho, forma, por seu conjunto de regras lingüísticas, confirmação e predição de forma e conteúdo, etc. ${ }^{10}$

As estratégias das quais o leitor faz uso são muitas e se apóiam nas regras gramaticais (sintáticas, semânticas do próprio sujeito), no reconhecimento do vocabulário (reconhecimento instantâneo da palavra no texto) e podem ser cognitivas ou metacognitivas. ${ }^{10}$ Estas são as operações que o leitor emprega orientadas por um objetivo consciente, permitindo que avalie o seu processo de ler. Quando isso não ocorre, podem aparecer dificuldades de compreensão. É comum, então, o leitor realizar a releitura do texto, a identificação ou a busca do significado de palavraschave, a organização de um resumo, a definição de conceitos, etc. ${ }^{10}$

As estratégias cognitivas de leitura são ações inconscientes do leitor, ações automatizadas das marcas formais do texto, ligadas ao princípio da coerência, como fatiamento sintático de um trecho, operação que o leitor realiza rapidamente e de diversas maneiras. ${ }^{10}$ Daí, referir-se a estratégia como procedimento inconsciente ou não que o leitor realiza ao se deparar com o texto:

- dividir o texto em unidades significativas;

- estabelecer relações de sentido e de referência entre as partes;

- buscar a coerência entre as idéias apresentadas no texto;

- ponderar a consistência das informações colhidas; inferir significado e o efeito pretendido pelo autor. 
A leitura é uma atividade que exige várias habilidades do leitor, o que demanda observar os aspectos extralingüísticos ou contextuais assim como os elementos lingüísticos e textuais. Deve ser considerada a leitura feita com um objetivo claro, a realização de inferências e levantamento de hipóteses, o acionamento de conhecimentos prévios, objetivando maior autonomia de pensamento.

Orlandi ${ }^{14}$ aponta que a pragmática conversacional preocupa-se com a intenção (ato ilocucionário) do interlocutor e com o reconhecimento dessa intenção pelo ouvinte (força locucionária) e supõe os efeitos de sentido entre os locutores, que não se extinguem no momento em que se fala. O diálogo proporciona o encontro do significado integrando aquilo que o sujeito tem na memória, de forma a alavancar esquemas, scripts que favoreçam a leitura compreensiva.

Nesta perspectiva, as condições de produção do texto, seu funcionamento, isto é, como o texto produz sentidos, considerando a sua espessura semânticalingüística e histórica são fundamentais para a discursividade. ${ }^{14}$ Há, no texto, uma ideologia expressa pelo autor que oferece indícios da significação por ele atribuída à realidade, modos de pensar construídos socialmente e ao longo do tempo que engendram uma memória discursiva.

Depreende-se, então, que a leitura é uma ação complexa que extrapola, em muito, a mera decodificação da palavra escrita. É uma ação multifacetada em que coexistem diferentes possibilidades de formulação de sentido.

\section{Os textos acadêmico-científicos: um gênero textual}

Neste estudo, concebe-se texto como qualquer produção lingüística, oral ou escrita que contém sentido completo e unidade. ${ }^{8}$

O texto possui uma materialidade (forma, marcas, vestígios), uma historicidade significante e significada, uma complexidade, pois é uma manifestação do funcionamento simbólico. ${ }^{14}$

$\operatorname{Furlan}^{7}(1998)$ especifica que a leitura de um texto teórico expressa um conhecimento de mundo e diferencia-se de outras formas de expressão simbólica, porque são sistematizados, organizados e metódicos considerando a tentativa de traçar caminhos e "esgotar" as explicações cabíveis, a fim de iluminar e encontrar possíveis respostas aos problemas do cotidiano da sociedade. O texto acadêmico tem a finalidade de expor o pensamento científico-filosófico de estudiosos sobre um determinado tema, propondo que os leitores analisem os dados apresentados, reflitam e possam reconstruir o texto compartilhando com o autor a problematização em pauta.

Os textos acadêmico-científicos pressupõem quase sempre um raciocínio dedutivo, em que a razão reflexiva permite seguir o pensamento do autor, o que se traduz numa disciplina intelectual. Estes textos preocupam-se em analisar o estado atual do conhecimento numa determinada área, compara e contrasta abordagens teórico-metodológicas, avalia a confiabilidade dos dados e informações e identifica lacunas, controvérsias e consensos. ${ }^{19}$

É pertinente observar que a intertextualidade está presente ao se fazer a leitura de textos acadêmicos científicos. A intertextualidade refere-se a um texto que contém elementos e/ou depende de textos já produzidos anteriormente. Ao emitir um ponto de vista, o autor do texto se remete a outros textos e autores, da mesma época ou não, estabelecendo um diálogo com eles, o que é comum ocorrer no texto acadêmico-científico, pois, normalmente, o autor utiliza conhecimentos prévios adquiridos em outros estudos que foram compreendidos, assimilados, refutados que são inseridos na sua produção para dar consistência à hipótese que quer demonstrar. ${ }^{14,8} \mathrm{O}$ texto acadêmico-científico costuma fazer uso, necessariamente, de citações diretas ou indiretas na sua elaboração.

Os textos acadêmico-científicos possuem um caráter dissertativo/argumentativo e descritivo, desvelando visão de mundo, uma tese que é sustentada cientificamente e formalizada por meio de uma linguagem técnica/padrão. Demonstram também exatidão e rigor na delimitação do objeto, de um fato ou fenômeno, buscando a comprovação e fundamentação exaustiva daquilo a ser comprovado.

Justamente por apresentar esses elementos, podese afirmar que instauram enunciados relativamente estáveis, marcados pela especificidade de uma esfera de comunicação. Verifica-se a existência de certo repertório que se assemelha quanto ao conteúdo temático, ao estilo verbal e a construção composicional, numa modalidade complexa de pensamento com os quais os alunos devem se familiarizar para que a leitura seja significativa, o que caracteriza o discurso secundário. Insere-se aí o discurso científico, o ideológico, textos legislativos, escritos literários e outros. O discurso primário caracteriza-se por uma comunicação verbal espontânea, própria das especificidades do cotidiano. Portanto, a natureza do enunciado não pode ser ignorada ${ }^{1}$ 
Sobre a leitura de textos acadêmicos, Resende e Pelandre ${ }^{17}$ (2005) revelaram que $20 \%$ lêem integralmente os livros e textos acadêmicos, $46,67 \%$ aprofundam a leitura, 6,67\% lêem com rapidez e superficialmente, 6,67\% não lêem textos acadêmicos. Dos quinze sujeitos participantes da pesquisa, $13,33 \%$ não sabiam ler ao ingressar na $1^{a}$ série do ensino fundamental e $26,67 \%$ afirmaram não haver alguma prática de leitura em sua vida familiar. Esses dados permitem dizer que a leitura, enquanto prática cultural e social, se constrói ao longo da formação

\section{A visão dos teóricos: um diálogo com o texto digital}

A leitura, em especial aquela feita a partir de textos acadêmico-científicos, exige do leitor a construção e reconstrução do saber ensinado, questionando as informações lidas para produzir um conhecimento autônomo. ${ }^{15,16,2}$

Os meios de comunicação contemporâneos, no caso, a tecnologia meditizada pelo computador pessoal (PC), inseriram uma ecologia de mensagens e textos diferente daquela existente até a metade do século XX, caracterizada por uma leitura "controlada" devido à escassez de publicações, de editoras, bibliotecas e mesmo de autores, entre outros fatores. ${ }^{11,5,4,3}$

Os novos suportes de leitura introduziram formas de ler e pensar que estão inseridas em contextos sociais. No caso, o suporte da tela do computador estende a variação das formas de ler e reforça a idéia de um leitor ativo, atuante e "conversador" com o autor do texto.

Admite-se que para se compreender o sentido de um discurso, adota-se uma atitude responsiva, ou seja, ao compreender um enunciado, está-se sempre concordando, discordando, refutando-o, acrescentando, dando assim a contra-palavra. ${ }^{1}$ Ao dialogar com os links, o leitor evidencia estes preceitos, pois emite uma reação ao clicar em um link e não em outro, ao seguir determinado roteiro e não outro.

$\mathrm{O}$ texto não é apenas um conjunto de símbolos escritos que precisam ser decodificados pelo leitor, mas um conjunto de enunciados que traduz uma intenção que imprime um caráter às palavras expressas, atribuindo-lhes um sentido. O enunciado abarca a expressão do pensamento (objeto) e o próprio enunciador. É a unidade real da comunicação verbal que implica a alternância de sujeitos falantes. O processo de construção de um hipertexto, a intra e intertextualidade criadas na relação entre textos, parágrafos, frases e palavras, além de sons e imagens, são promotores de "dialogia", inerente a qualquer enunciado e as particularidades do gênero que permeiam a variedade dos discursos, pois considera o vinculo existente entre a vida e a língua. ${ }^{1}$

O sujeito apreende o conhecimento "por simulação”, processo característico da cultura informática, porém, os critérios e reflexos mentais se apóiam em tecnologias intelectuais anteriores. ${ }^{11}$

Chartier ${ }^{5,4,3}(1999,2001,2002)$ compartilha da mesma idéia, defendendo a leitura como uma "prática discursiva", o que permite percebê-la engendrada no contexto sócio-politico-economico-cultural. Destaca a necessidade de se atentar à materialidade dos textos e à corporalidade dos leitores, de perceber os sentidos construídos nas relações concretas entre o leitor e o texto, através das quais se estabelecem as apropriações do mesmo, pois a leitura "é sempre apropriação, invenção, produção de significados". ${ }^{5}$

O texto é um conjunto de idéias, fragmentos, palavras que organiza uma rede de conceitos, porque está diretamente relacionado com o seu entorno. Ele organiza uma rede semântica que contribui para remodelar ou construir outros contextos, criando uma espécie de mapa compreendido como a elaboração de um universo de sentidos: o hipertexto. Este é um conjunto de nós ligados por conexões - palavras, páginas, imagens, gráficos, etc. que possibilita ao leitor entrar em conexão com outros textos, outras informações, desenhando um percurso peculiar e complexo. ${ }^{11}$

Entende-se hipertexto em oposição ao texto linear como um "texto estruturado em rede", o que significa que "é constituído por nós (os elementos de informação, parágrafos, páginas, imagens, seqüências musicais, etc.) e de links entre esses nós, referências, notas, ponteiros, 'botões' indicando a passagem de um nó a outro", destacando a agilidade da navegação, da passagem de um nó para outro, o que caracteriza um texto "móvel". 11

O hipertexto permite o emprego de ferramentas de estruturação e consultas de informação. Os textos não são organizados linearmente e permitem individualizar a consulta, com enunciados únicos, mas sistemas de menu e lier que por meio das ferramentas de busca ampliam as informações sobre um tema. ${ }^{18}$

Os princípios fundamentais são:

- a constante transformação da rede hipertextual demandada por um tempo flexível;

- a infinidade de conexões possíveis devido à heterogeneidade das associações; 
- a multiplicidade de interpretações favorecida pelos elementos de conexão;

- a exterioridade que abrange a composição e recomposição da rede em função de novos elementos incorporados;

- a topologia ou caminho escolhido e

- a mobilidade infinita de criar ramificações desenhando outros cenários de sentido. ${ }^{11}$

Mascuschi $^{12}$ (1999), de forma semelhante, indica as características do hipertexto no meio eletrônico:

- não-linearidade (flexibilidade que possibilita diferentes ligações e caminhos de navegação);

- volatilidade (não tem estabilidade, pois as escolhas são passageiras e as conexões estabelecidas por seus leitores);

- topografia (o hipertexto não é hierárquico nem tópico, e sua escrita e leitura são infinitos);

- fragmentariedade (a constante ligação de breves fragmentos sem um centro regulador imanente impede o autor de controlar o tópico e o leitor);

- acessabilidade ilimitada (acessa-se todo tipo de fonte: dicionários, enciclopédias, museus, obras cientificas, literárias, arquitetônicas etc.);

- multisemiose (interconecção simultânea da linguagem verbal com a não-verbal (musical, cinematográfica, visual, gestual) de forma integrativa;

- interatividade (interconexão interativa do leitor com múltiplos autores);

- intertextualidade, marcada pela recursividade de textos.

Assim, o leitor-navegador cria modos de ler o texto de forma semelhante ao que está acostumado a adotar para o suporte impresso, como o livro. Neste, aplica estratégias de leitura como a identificação de títulos, subtítulos, sumário, índices, referências, notas de rodapé, paginação e outras caracterizadas como interfaces que instituem dispositivos lógicos, classificatórios e espaciais que facilitam a apropriação do texto pelo leitor. ${ }^{11,5,4,3}$

No entanto, há que se destacar que a textualidade eletrônica compromete o leitor com outra técnica de leitura, uma nova relação com o texto devido a uma materialidade particular, pois introduz uma aproximação diferenciada, de inscrição no texto, ${ }^{5,3,13}$ pois este é móvel, aberto e maleável. O leitor pode intervir no texto, recortar, colar, deslocar, apagar, recompor as unidades textuais, de forma ágil, pois a velocidade da máquina permite ações múltiplas, embora o gerenciamento da coleta de informações não seja alea- tório, pois se entende que o leitor possui um objetivo em mente ao ler. Porém, na tela, pode perseguir uma informação, "dar uma olhada", pois o hipertexto convida a ações deste tipo. É uma rede original de interfaces.

Neste contexto, um estudo, realizado em 1970 e 1980, mostrou que a leitura na tela do computador é 15 a $20 \%$ mais lenta que a leitura do texto impresso e que aquela provoca fadiga, pois gasta mais tempo (10 min) do que a leitura impressa. Há outros fatores intervenientes:

- a luminosidade da tela,

- o contraste de caracteres,

- a distância,

- a posição e

- a estabilidade da imagem.

Diz que a leitura é mais eficaz, mais rápida e mais fácil no texto impresso que na tela. ${ }^{18}$

É consenso que, no hipertexto, a informação não é linear. ${ }^{18,11,5,4,3}$ As páginas não seguem uma ordem pré-estabelecida, mas formam um conjunto estruturado por um sistema de link (ligação). A partir de uma determinada página, é possível acessar outras. Cada opção é materializada por hiperlink, em geral, uma palavra ou expressão sublinhada, destacada, em cor específica. Os links entre as páginas são determinados por conteúdos e critérios associativos, favorecendo a compreensão da informação, por que o seu funcionamento é semelhante à mente humana: a associação de conhecimentos.

A possibilidade de, ao ler o texto, encontrar um termo ou expressão, clicar em cima deste e encontrar outra página com informações sobre o assunto amplia a construção de aprendizagens significativas e subsidia um trabalho intelectual com estruturas mais complexas. Permite, também, o acesso a mesma informação apresentada de diferentes formas: outros textos, ilustração, estudos de caso, problemas a resolver. O texto impresso também utiliza recurso para facilitar a compreensão do leitor: notas explicativas ao pé da página, índices remissivos, glossários, referências cruzadas, mas, não é comum o leitor usar estes recursos, principalmente se demanda um esforço maior ou se perturba o curso normal da leitura. ${ }^{18}$

Gordon e cols. apud Rouet ${ }^{18}$ (2001), em 1988, solicitaram a 24 estudantes que lessem um texto considerado como leitura recreativa e um texto técnico de estudo, na tela, com o intuito de verificar o entendimento das idéias-chave que os textos continham. Descobriram que os estudantes se saíram melhor na com- 
preensão do texto de entretenimento e acharam a versão hipertextual mais difícil de ser utilizada. Nos textos técnicos, o resultado não apresentou diferença significativa entre a forma linear ou hipertextual. Os autores concluíram que não é seguramente adaptado a situações em que a leitura não visa explicitamente à aprendizagem ou memorização

Foss, em 1989, revelou que os alunos, ao executarem a leitura hipertextual, encontram 3 dificuldades:

- tendem a se perder dentro do próprio sistema de busca (estratégia de pesquisa);

- esquecem as informações iniciais que moveram a busca (sobrecarga da memória);

- perdem tempo manipulando a interface (gestão de busca). ${ }^{18,13}$

Evidencia-se que a leitura hipertextual exige uma divisão qualitativa de buscas diferentes do texto linear. A leitura hipertextual necessita da capacidade relacional que mobiliza anotações visuoespaciais da memória de trabalho. ${ }^{18}$

O texto linear tem uma organização seqüencial, em capítulos e subpartes. É unidimensional e de fácil manuseio. Os links semânticos transversais - referências cruzadas - podem sem compreendidos pelo leitor, mas, não são recursos utilizados por ele. Por outro lado, a estrutura hipertextual é multidimensional e mais difícil de ser compreendida. O leitor necessita de marcas metatextuais explícitas e reconhecíveis: menus, títulos, na forma de listas ou fichas de conteúdo, etc., para embasar a leitura eficiente. A compreensão do hipertexto varia de acordo com o tipo de textodescritivo ou causal, o tipo de busca e as características individuais do leitor. ${ }^{18}$

\section{A METODOLOGIA DO ESTUDO}

Os respondentes eram alunos cursistas do $7^{\circ}$ e $8^{\circ}$ períodos do curso de odontologia da uma universidade particular localizada na zona oeste da cidade do Rio de Janeiro, matriculados na disciplina Trabalho de Conclusão de Curso sob Orientação Docente, em 2009.

O questionário aplicado em 46 sujeitos constava de um levantamento sobre idade, sexo, região de moradia, período matriculado, com 11 perguntas fechadas e 2 de caráter aberto sobre as formas de leitura de estudo feitas no meio eletrônico, cujos resultados foram organizados através do programa Mycrosoft Excel, caracterizando um estudo exploratório.

A coleta de dados ocorreu durante a aula da disciplina e não se solicitou a identificação dos estudan- tes. Além disto, foram entrevistados 3 formandos com o intuito de esclarecer/complementar aspectos relevantes. As entrevistas individuais foram realizadas em sala reservada, gravadas, após o consentimento do entrevistado e transcritas.

\section{A leitura de textos acadêmico-científicos no meio eletrônico: alguns indícios}

Não há ainda uma preferência acentuada para a leitura de textos acadêmicos feitos na internet. Dezessete alunos lêem material de estudo tanto impresso quanto eletrônico. Estes alunos ressaltam que a leitura do texto eletrônico se caracteriza por ser rápida, não escolhem textos longos. Denotam que não há, no início, uma preocupação com o teor do texto e sua informatividade, seguindo a lógica de distinguir a proposta do texto anunciada na introdução, a base teórica, a metodologia empregada, os resultados obtidos, as argumentações e considerações finais. À primeira vista, o tamanho do texto é mais importante.

Alguns alegam que a possibilidade de utilizarem o celular para baixar arquivos e ler os textos neste aparelho, em qualquer lugar, facilita o acesso; outros acreditam que há maior facilidade de acessar periódicos atualizados na internet e que a seleção de conteúdos (assuntos) é facilitada pela ferramenta de busca empregada. Em princípio, os alunos denotam preocupação com a agilidade da obtenção da informação e não com o teor da leitura.

Outros 14 alunos optam pela leitura de textos eletrônicos, porque consideram ser mais confortável e favorecer a obtenção de informações atualizadas, independente de onde a informação seja localizada. A facilidade de acesso (10), a diversidade das informações, maior motivação gerado pelo senso de pesquisa e menos monotonia foram as justificativas dadas. Sete não justificaram a escolha. Pouco mais de $20 \%$ dos estudantes preocupam-se com o objetivo da leitura, em pensar o que os leva a buscar a leitura de um texto sobre determinado tema na internet.

Há 16 alunos que preferem a leitura de estudo na forma impressa. Indicam que esta é menos cansativa, mais aprofundada e confiável. Acreditam que a leitura no computador pessoal cansa o corpo devido à posição, sentada e ereta; particularmente, cansa os olhos devido à luminosidade da tela. Dizem que a leitura aprofundada relaciona-se ao tipo de texto lido - teses, dissertações, artigos - e exige uma leitura cuidadosa, que respeite os critérios da metodologia científica, demandando mais tempo na frente da tela e exigindo maior concentração. São considerados tex- 
tos densos e mais complexos ${ }^{9,6,14}$ que demandam estratégias de leitura, o que implica a explicitação de uma gestão cognitiva adotada, ${ }^{18}$ como alguns alunos assinalam mais adiante. Um dos entrevistados prefere o livro para estudar, complementando as anotações de aula. Grava a aula e passa a limpo as informações: o livro é mais completo, com informações corretas e precisas. Não considera os benefícios que a busca do material eletrônico pode trazer.

Quanto ao gênero textual acadêmico-científico que é acessado na tela do computador, talvez influenciados pela disciplina em curso, 26 alunos consultam teses, dissertações e artigos científicos, porque são mais especificos, apresentam uma revisão de literatura que, em geral, representa o estado da arte da área e contêm idéias novas; 3 não têm hábito de ler material eletrônico para estudo; 11 costumam ler ensaios científicos, porque são mais curtos e cansam menos a vista; 1 aluno lê textos eletrônicos, desde que não sejam longos e apenas 3 costumam ler livros eletrônicos contrariando a posição de 2 colegas que afirmam não haver livro da área de odontologia disponível on line. Na verdade, são poucas as editoras que disponibilizam, na internet, obras na íntegra, nesta área. Além disto, os alunos reforçam indícios de que a leitura eletrônica está atrelada à dimensão do texto.

Os leitores de textos eletrônicos acadêmicos justificam tal escolha em função da agilidade para a busca do material; da facilidade de aquisição dos textos, posto que algumas bases de dados os disponibilizem gratuitamente ou por meio de compra. Outros dizem que lêem na tela, porque os textos são longos e a impressão de muitas folhas aumentaria o custo do material.

Um aluno entrevistado complementa que, nas aulas de informática, teve informações sobre os sites confiáveis e embora não se considere uma pessoa plugada, observou que os sites americanos são ricos em disponibilizar pesquisas. Ele sinaliza uma discussão importante que deve ocorrer em sala, sobre a mediação do docente em relação aos sites confiáveis. Considero que estes são aqueles em que o material disponível passa por uma avaliação de uma comissão científica, filiados a base de dados vinculados a universidades e grupos de pesquisas reconhecidos academicamente, além de associações de classe, etc.

Quando argüidos sobre um exemplo ou titulo de um material eletrônico consultado, 13 alunos não responderam, 2 não lembravam, 20 consultaram artigos cientificos e identificaram o titulo dos mesmos e dentre eles, 5 não conseguiram lembrar o titulo. $\mathrm{O}$ restante citou a monografia (impressa) como fonte de consulta, encontrada na biblioteca do campus.

A forma de busca utilizada para encontrar o texto acadêmico é a base de dados como o Bireme (6), Scielo (3), Medline (2), mas a maioria usa ferramentas de busca como o Google Acadêmico (14). Apenas 2 alunos procuram informações em sites indicados pelos docentes. Sobre isso, 3 entrevistados apontam que os professores não costumam indicar sites:

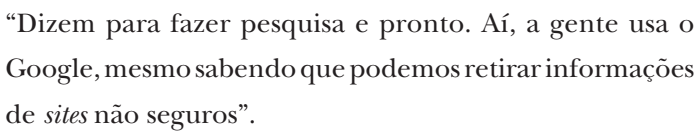

Do total de alunos, 17 não responderam, o que deixa transparecer pobre conhecimento do que eles mesmos nomeiam de sites confiáveis.

Sobre o uso da base de dados, os alunos mostram não ter domínio sobre esta ferramenta: Bireme, Pubmed e Scielo, respectivamente, são reconhecidos pela maioria dos alunos e desconhecidos, na sua totalidade, bases como Science Direct, Portal Capes, Comut e Ariel.

O local preferido para a leitura no meio eletrônico é o computador pessoal de casa (44), embora 21 alunos morem próximo à Universidade que dispõe de amplo laboratório de informática e acesso ao Portal de Pesquisa. Apenas um utiliza a sala de informática da universidade e outro aluno afirma não ler textos acadêmico-científicos no PC.

A freqüência de leituras deste gênero no meio eletrônico, durante a semana, é assinalada por 11 alunos que o fazem apenas $1 \mathrm{vez} ; 15$ alunos afirmam acessarem 2 vezes/semana a internet para a busca de texto científico e apenas 6 dizem que realizam leitura de estudo no meio eletrônico mais de 4 vezes/semana. Constata-se que os alunos não dedicam muito tempo para a leitura de estudo no meio eletrônico. Os 3 entrevistados buscam informações na internet para trabalhos, fazendo uma distinção entre estes e estudo. O estudo está vinculado a preparação para prova e, conseqüentemente, não usam material da internet.

Embora os dados demonstrem que a maioria dos estudantes não faz uso da leitura do texto eletrônico para estudar, 14 deles prefere a impressão do texto ao invés de ler na tela (2), porque alguns textos estão disponíveis apenas para a leitura, impedindo o destaque da partes significativas ou a escrita nas margens. Alegam que é comum o material sobre odontologia ser apresentado na língua estrangeira e nem sempre 
a dominam (3).

Como utilizam as ferramentas de busca, principalmente o Google, costumam encontrar sites em manutenção, textos que são sínteses de outros, contendo informações muito resumidas. Tal situação pode promover no estudante o desinteresse de saber de onde vem a informação ou quem é o autor, caso não observe um sistema de busca criterioso, confirmando a fidedignidade das informações apresentadas.

É relevante destacar que estes apontam para a polifonia discursiva, pois, como resultado de uma pesquisa, o leitor/navegador obtém uma lista considerável de indicações que estão disponibilizadas na rede. Ao mesmo tempo, assinalam um paradoxo, pois se sabe que não se consegue ter acesso a todas as informações, pois o próprio termo acionado restringe as conexões a determinados endereços, excluindo outros tantos sites, homepages, páginas, etc. podendo gerar uma espécie de stress cognitivo, pois o tempo todo o aluno deve tomar decisões fortes e difíceis. ${ }^{18,13}$

Quanto ao armazenamento das informações encontradas na internet, alguns usam as mesmas ferramentas próprias da leitura do texto impresso: fazem um resumo (7) ou utilizam a estratégia do corte/colagem e/ou sublinham as partes mais importantes, quando isto é permitido pelo tipo de arquivo em tela, reforçando que o leitor cria modos de ler o texto, dispositivos lógicos, classificatórios e espaciais para compreender e assimilar as idéias do texto. ${ }^{11,5,4,3}$

Ao mesmo tempo em que os alunos realizam a leitura de caráter científico no meio eletrônico, o texto impresso, aquele em que foi feito o download ou anotações de aula, capítulo de livros e outros são mencionados como opções viáveis: 30 alunos reportam que fazem uma leitura inicial do texto na íntegra, uma segunda leitura marcando aspectos importantes e quando necessário, um resumo. Indicam que ler com o texto na mão é mais fácil, porque podem organizar melhor as idéias. Em outras palavras, transitam nas folhas de papel e nas páginas virtuais. Um dos entrevistados diz que embora a leitura de um livro seja mais completa, a linguagem do autor é sempre difícil. Ai, a internet ajuda, pois você encontra o conteúdo mais simples. As gravuras ajudam muito a compreensão do texto. Outro menciona que costuma salvar em pastas o material selecionado para posterior leitura.

Dentre as dificuldades encontradas na leitura de textos eletrônicos, destacam-se àquelas relativas à compreensão do texto, pois os estudantes se reconhecem com dificuldades de leitura (5), porque não adotam uma metodologia de leitura semelhante às estratégias recomendadas; ${ }^{10} 10$ alunos justificam a falta de base científica para a compreensão do material, ${ }^{2}$ o que revela que, independente do suporte, a dificuldade existiria. Os textos acadêmicos exigem do estudante certa proximidade com o conteúdo do texto, o manejo de trabalhar com a previsibilidade (suposições) do texto cujas informações são comprovadas ou não durante a leitura, o domínio da linguagem, a descoberta dos aspectos teóricos que embasam o texto, a identificação da problematização, as argumentações sobre os dados apresentados e uma posição crítica-reflexiva. Estes alunos deixam transparecer que as dificuldades de leitura também podem estar vinculadas ao conhecimento de mundo que compõe a trajetória da cada leitor.

Os aspectos corporais são considerados desfavoráveis à medida que a leitura em tela provoca cansaço visual (7), dor de cabeça (3); a posição sentada por tempo prolongado é cansativa (2); a pouca concentração destinada a apreensão das informações porque a inserção de links implica a perda do objetivo inicial (5). Um aluno costuma pular os links, pois a leitura fica infinita, pois são milhares de informações, corroborando as idéias de $\operatorname{Rouet}^{18}$ (2001).

\section{As intervenções possíveis dos docentes: por uma prática de leitura acadêmica no ambiente virtual}

A leitura de textos acadêmicos, em suporte eletrônico, é uma realidade nebulosa, porque os estudantes não possuem domínio suficiente em termos de conhecimento prévio e de manejo sobre as ferramentas necessárias para navegarem em "águas tranquilas" e encontrarem "portos" seguros quanto às informações advindas dos sites. Como encontrar informações científicas fidedignas? Como ler para aproveitar o potencial do conhecimento apresentado no texto acadêmico?

Acredito que, independente do suporte do texto, eletrônico ou não, o docente tem a responsabilidade de orientar o estudante sobre a maneira de ler um texto acadêmico, cuja natureza não linear do mesmo, remete a lançar mão de marcas específicas alinhavadas no corpo do texto. O professor tem o compromisso de tornar o leitor um explorador de possibilidades.

Os dados obtidos apontam que é necessário haver uma compreensão de que a leitura não é um instrumento, uma ferramenta para acessar os saberes acumulados nos diversos suportes, impressos ou eletrônicos. Ela é uma construção intrínseca ao desenvolvimento intelectual. 
A leitura do texto científico eletrônico ou não deve ter um encaminhamento do docente, chamando a atenção para as suas características enquanto gênero textual que pode assumir um aspecto mais descritivo, argumentativo ou expositivo e a organização das partes que constituem o texto.

Em função dos aspectos revelados pelo estudo, acredito ser fundamental a articulação entre processos de recuperação de elementos cotextuais e contextuais e dos aspectos pragmáticos da leitura; o reconhecimento das funções das conexões lógicas do texto através de expressões, conjunções, etc.; o treinamento do aluno para a percepção das marcas textuais relevantes para a identificação das intenções do autor, ainda mais considerando a acessibilidade crescente do estudante aos textos eletrônicos.

\section{CONSIDERAÇÕES FINAIS}

O estudo revelou que o mundo digital, onde há uma diversidade de textos, em especiais, aqueles nomeados de leituras acadêmico-científicas, faz parte do cotidiano do aluno.

No entanto, os alunos ainda não demonstraram o letramento proporcionado pela tecnologia, pois, dispensam links, o uso de base de dados e preocupam-se em ler texto curtos, no computador, porque mais fáceis de serem compreendidos.

Por outro lado, o emprego da metodologia de leitura utilizada no texto impresso é a mesma usada para o texto eletrônico. Não há clareza se fazem uso, no entanto, das ferramentas disponibilizadas pelos programas.

Os aspectos físicos quanto à leitura no meio eletrônico relacionam-se a sensações negativas que tornam a leitura árdua e cansativa.

$\mathrm{O}$ uso de bases de dados é um fator a ser implementado por parte dos docentes, de forma a ampliar o universo da pesquisa e estudo dos alunos.

Concluiu-se que os alunos não são, em sua maioria, navegadores/leitores de textos eletrônicos voltados para o estudo acadêmico, o que implica a implementação de uma pedagogia da leitura e o aprimoramento do letramento na cibercultura. No ensino superior, ainda é preciso "trabalhar" a leitura, se há a intenção de formar sujeitos que interfiram no seu entorno. Ao professor cabe o imprescindível papel de mediador do conhecimento. Aliando seu conhecimento ao processo que se instaura em sala de aula, pode estabelecer relações de interação, possibilitando um espaço de discussão sobre as leituras produzidas por todos, tendo em vista que o gênero tex- tual científico obriga o leitor a aprofundar conceitos, trabalhar os argumentos apresentados, levantar os pressupostos ideológicos, filosóficos, históricos e epistemológicos que estão subjacentes ao texto.

\section{ABSTRACT}

Dentistry students and their reading of academicscientific texts in the virtual world

Seeking to understand the reading practices of students regarding the reading of academic-scientific texts available in the virtual world, the study asked how students perform in the reading of these texts. How do they interact with old and new reading technologies? Chartier, Rouet and Levy laid the foundation for the study. The questionnaire was the instrument applied to 46 students from the $7^{\text {th }}$ and $8^{\text {th }}$ semesters of a private university. Three students were interviewed to clarify aspects brought to light by the questionnaire. The study found that the digital world is part of the daily lives of students. However, they have not yet demonstrated the literacy provided by the technology, because they dispense with links and with using the database, and prefer to read short printed or electronic texts, because these are easier to understand. They use the same reading strategy for these types of texts. It can be concluded that students are not proficient/browsers readers of electronic scientific texts.

\section{DESCRIPTORS}

Dental education. Eletronic reading. Academic reading. .

\section{REFERÊNCIAS}

1. Bakhtin, M. Os gêneros do discurso. In: Bakhtin, M. Estética de criação verbal. 3.ed. São Paulo: Martins Fontes; 2000. p. 277-326.

2. Castello-Pereira, L. M. Leitura de estudo: ler para aprender e estudar para aprender a ler. Campinas: Alínea; 2003. 208p.

3. Chartier, R. Os desafios da escrita. São Paulo: EdUNESP; 2002.144 p.

4. Chartier, R. A revolução do texto eletrônico. In: Chartier, R. Cultura escrita, literatura e história. Porto Alegre: ArtMed; 2001. p.139-159.

5. Chartier, R. A aventura do livro: do leitor ao navegador. São Paulo: EdUNESP; Imprensa Oficial do Estado; 1999.159 p.

6. Coracini, M. J. R. F. (Org.). Leitura: decodificação, processo discursivo...? In: Coracini, M. J. R. F.O jogo discursivo na aula de leitura: língua materna e língua estrangeira. Campinas, S.P: Pontes; 1995. p. 13-20.

7. Furlan, V. I. O estudo de textos teóricos. In: Carvalho, M. C. M. de. (Org.). Construindo o saber. 8.ed. Campinas, S.P.: Pa- 
pirus; 1998. p. 119- 129.

8. Goldstein, N; Louzada, M.S.; Ivamoto, R. O texto sem mistério: leitura e escrita na universidade. São Paulo: Ática; 2009. 200 p.

9. Kato, M. No mundo da escrita: uma perspectiva psicolingüística. 7.ed. 4.impr. São Paulo: Ática; 2002.

10. Kleiman, A. Oficina de leitura: teoria e prática. Campinas, S.P.: Pontes; $1993.102 \mathrm{p}$.

11. Levy, P. As tecnologias da inteligência: o futuro do pensamento na era da informática. Rio de Janeiro: Editora 34; 1993.203 p.

12. Mascuschi, L. A. O Hipertexto como um novo espaço de escrita em sala de aula. IV Fórum de estudos Lingüísticos, Língua Portuguesa em Debate. UERJ, 1999.

13. Mello, C. T. V. de. A análise do discurso em contraponto à noção de acessibilidade ilimitada da Internet. In: Mascuschi, L. A.; Xavier, A.C. Hipertexto e gêneros textuais: novas formas de construção de sentido. 2. ed. Rio de Janeiro: Lucerna; 2005. p. 135- 143.

14. Orlandi, E. Análise de discurso e interpretação. In: Orlandi, E. Discurso e texto: formulação e circulação dos sentidos. Campinas: Pontes; 2001. p. 19-30.

15. Rangel, J.N.M. A leitura e a formação humanística do estudan- te de odontologia: processos em formação. Revista da ABENO. 2006a, 1(6), 20-27.

16. Rangel, J.N.M. A leitura na universidade. In: Rangel, J.N.M. Caminhos interdisciplinares na odontologia. Rio de Janeiro: Rubio; 2006b. 72 p.

17. Resende, M. C. F.; Pelandre, N. L. Letramento e leituras do leitor adulto: práticas marcadas pela história e sociedade. UFSC. 2005.[15 jan.2001]. Disponível em: http:/ / www.anped. org.br/reunioes/28/textos/gt10/gt10352int.rtf.

18. ROUET, Jean-François. Aspects cognitifs des nouvelles technologies de l'information. In: ROUET, Jean-François. Les Activités Documentaires Complexes-Aspects Cognitifs et Développementaux. p. 106 - 137, abr. 2001. Disponível em: < http://www.mshs.univpoitiers.fr/laco/Pages_perso/Rouet/Textes.htm >

19. Severino, A. J. Metodologia do trabalho científico. 21.ed.rev. e ampl. São Paulo: Cortez; 2000. 279 p.

Recebido em 09/03/2010

Aceito em 15/06/2010 